Derek S. Wheeler

\title{
Do you know how much it costs?
}

Received: 27 May 2015

Accepted: 3 June 2015

Published online: 23 June 2015

(C) Springer-Verlag Berlin Heidelberg and ESICM 2015

D. S. Wheeler

Department of Pediatrics, University of Cincinnati College of Medicine, Cincinnati, USA

\section{S. Wheeler $(\bullet)$}

Cincinnati Children's Hospital Medical Center, 3333 Burnet

Avenue, Cincinnati, OH 45229-3039, USA

e-mail: derek.wheeler@cchmc.org

Tel.: (513) 636-4259

Economics, as a scientific discipline, deals with the production, distribution, and consumption of goods and services and is chiefly concerned with the allocation of scarce resources. From an economics standpoint, if something is scarce, it will have market value. There are two laws that every student of economics learns in the first week of the first class during the first year of their education. The first law, known very simply as the law of supply, states that, all other factors being equal, as the price of a good or service increases, the quantity of that good or service offered or sold by the suppliers of that good or service will increase. The second law (known as the law of demand) is just as elegant and states that, all other factors being equal, as the price of a good or service increases, consumer demand for that good or service will decrease. Importantly, in a perfectly competitive market, the equilibrium price of a good or service occurs at the point at which the quantity demanded and quantity supplied are equal (i.e., at the point at which the downwardsloping demand curve and the upward-sloping supply curve intersect each other, see Fig. 1). In other words, if the supply of a good or service is low, the market price will rise, as long as there is sufficient demand from consumers. If there is excess supply of a good or service, the market price will fall. In a similar way, as long as there is sufficient supply of a good or service, if consumer demand for that good or service is low, the market price will fall. Conversely, if the demand of the good or service increases, the market price will rise.

Many economists would argue that the best way to allocate a scarce resource is to rely upon free market principles. A perfectly competitive market is defined as a market where prices are determined entirely by the laws of supply and demand, with little or no government control. There are three fundamental criteria that are necessary for perfect competition:

1. There are no barriers to entry or exit for buyers and sellers.

2. There are many buyers and sellers in the market, so that no single buyer or seller has the market power to set the price of a good or service on his or her own.

3. Every buyer and every seller has the same information that he or she can use to make rational decisions.

The necessary conditions for perfect competition do not exist in health care today, even in the USA. For example, the entry of new providers and hospitals are limited by licensure requirements, board certification, and certificate of need (CON) laws [1]. At least in the USA, there have been a growing number of hospital mergers and acquisitions and a trend for greater vertical and horizontal integration [2]. Collectively, consolidation and integration reduces the number of suppliers of health care services, creating conditions less favorable to perfect competition. Finally, and perhaps most important is the issue of information asymmetry. Health care providers generally know much more about providing care than patients. Neither the quality nor the price of health care services is readily available to the average patient as consumer. On the flip side, patients may not fully disclose information about their condition to either the insurance provider or health care provider [3]. 

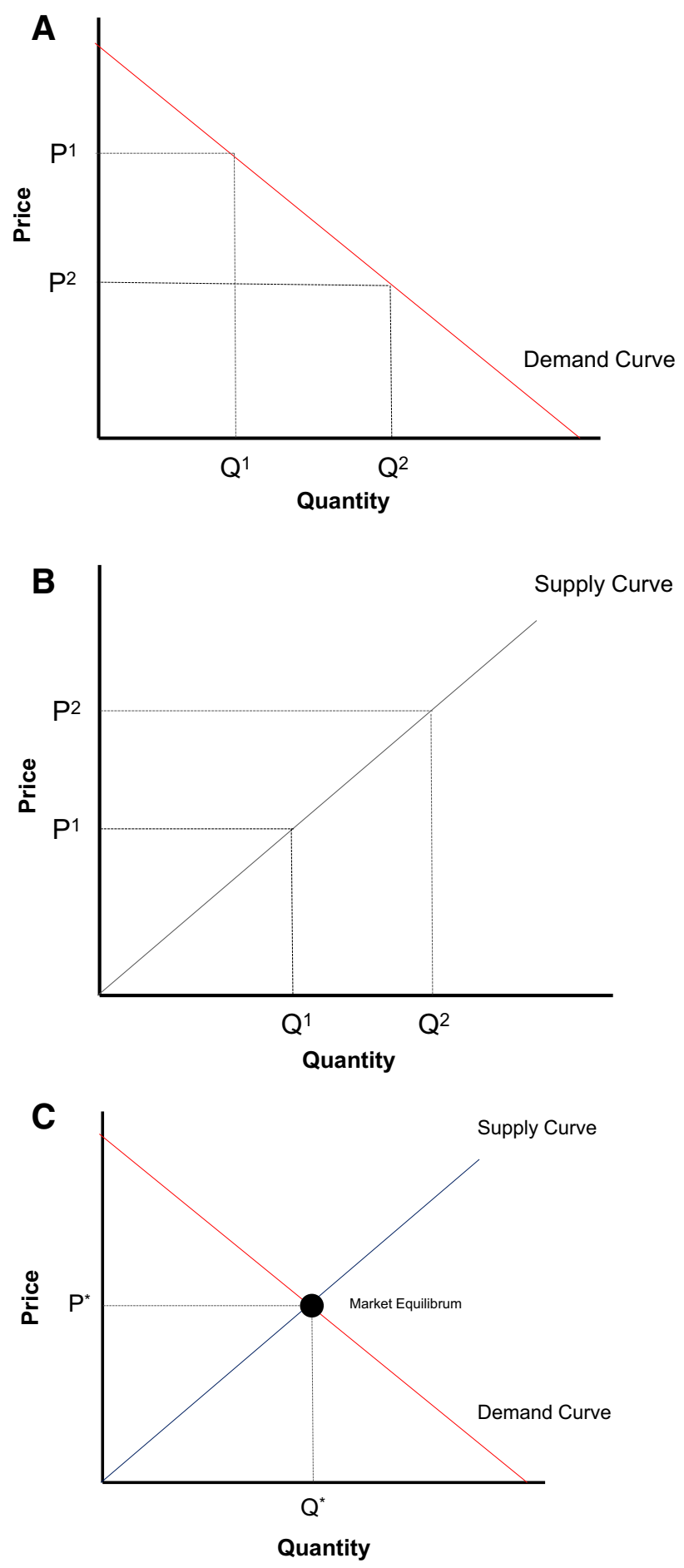

The lack of quality and price transparency in health care is a pervasive problem, even in countries with universal access and coverage. Several studies have shown that physicians are generally unaware of the cost of nearly all of the care that they provide [4, 5]. Physicians are directly or indirectly responsible for nearly all of the care that is delivered. The theory is that if physicians fully
4Fig. 1 a The demand curve is always downward sloping. By convention, price is always on the $y$ axis and quantity is always on the $x$ axis. In a perfectly competitive market, assuming everything else is constant, as the price decreases from $P^{1}$ to $P^{2}$, the quantity of the good or service demanded by the consumer increases from $Q^{1}$ to $Q^{2}$. b The supply curve is upward sloping. In a perfectly competitive market, assuming everything else is constant, as the price increases from $P^{1}$ to $P^{2}$, the quantity of a good or service produced by the supplier increases from $Q^{1}$ to $Q^{2}$. c The supply curve and demand curves intersect at the equilibrium price. In a perfectly competitive market, as long as supply and demand remain constant (i.e., neither the supply curve or demand curve shift in position or slope), the quantity of a good or service that is demanded by the consumer will equal the quantity supplied by the supplier at $Q^{*}$, which also occurs at price $=P^{*}$

appreciated the costs of the services and treatments that they provide, the rising health care costs could be better controlled. Moreover, greater awareness of the costs of care could be one way of leveraging free market principles to lower costs, according to the laws of supply and demand discussed above $[6,7]$.

There is great interest in reducing the cost of care in the intensive care unit (ICU) setting [8-10]. ICU care accounts for a significant proportion of total health care costs [11], accounting for between 17.4 and $39.0 \%$ of all hospital costs in some studies [11-14]. Reducing ICU costs will therefore have a significant impact on the health care costs as a whole. As mentioned above, one potential strategy for reducing the costs of care in the ICU is through increasing physicians' awareness of these costs. Most of the aforementioned studies on physicians' awareness of health care costs have been performed outside the ICU setting.

With this in mind, Hernu and colleagues [15], in a recently published article, surveyed over 1300 physicians working in 99 French ICUs with a response rate of $83 \%$. The survey questionnaire asked physicians to estimate the cost of 46 different treatments in one of four treatment groups (drugs, blood products and derivatives, imaging modalities, and laboratory tests). The survey also included two clinical scenarios, septic shock due to communityacquired pneumonia and hemorrhagic shock occurring under vitamin $\mathrm{K}$ antagonist treatment. Physicians were asked to estimate the cost of all treatment for a 7-day ICU stay for these two conditions. Only 315/1092 (29\%) of the physicians' estimates were within $50 \%$ of the true cost, as determined by the French national average costs. Drug costs were the most significantly underestimated costs, and only imaging modality costs were routinely overestimated. Most physicians tended to overestimate the cost of relatively inexpensive medications and significantly underestimate the cost of expensive medications. These trends persisted when physicians were asked to estimate the cost of care in the two clinical scenarios. Younger physicians were more likely to incorrectly estimate the cost of care compared to older physicians. Somewhat surprisingly, female physicians 
were also more likely to incorrectly estimate the cost of care compared to male physicians.

Increasing cost awareness may turn out to be an important strategy to reducing the cost of care in the ICU setting. Greater cost transparency will certainly help alleviate some of the information asymmetry that exists in health care today. The study by Hernu and colleagues [15] provides important background information with which we may begin to tackle this issue. While the fact that older physicians more accurately estimate costs compared to younger physicians is intuitive (with age comes experience!), the reasons for why there is a gender difference in how accurate physicians are in estimating costs deserves further study. Clearly, we need to do a better job of educating physicians on how their decisions impact the overall cost of care. Do you know how much care in your ICU costs? Maybe it is time to find out.

\section{References}

1. Hsiao WC (1995) Abnormal economics in the health sector. Health Policy 32:125-139

2. Tsai TC, Jha AK (2014) Hospital consolidation, competition, and quality: is bigger necessarily better? JAMA 312:29-30

3. Bodenheimer T (2005) High and rising health care costs. Part 1: seeking an explanation. Ann Int Med 142:847-854

4. Allan GM, Lexchin J, Wiebe N (2007) Physician awareness of drug cost: a systematic review. PLoS Med 4:1486-1496

5. Allan GM, Lexchin J (2008) Physician awareness of diagnostic and nondrug therapeutic costs: a systematic review. Int J Technol Assess Health Care 24:158-165

6. Preker A, Harding A (2003) The economics of hospital reform: from hierarchical to market-based incentives. World Hosp Health Serv 39(3):3-10
7. Vaithianathan R (2006) Health insurance and imperfect competition in the health market. J Health Econ 25:1193-1202

8. Kahn JM (2006) Understanding economic outcomes in critical care. Curr Opin Crit Care 12:399-404

9. Halpern NA (2009) Can the costs of critical care be controlled? Curr Opin Crit Care 15:591-596

10. Pastores SM, Dakwar J, Halpern NA (2012) Costs of critical care medicine. Crit Care Clin 28:1-10

11. Halpern NA, Pastores SM (2010) Critical care medicine in the United States 2000-2005: an analysis of bed numbers, occupancy rates, payer mix, and costs. Crit Care Med 38:65-71

12. Halpern NA, Pastores SM, Greenstein RJ (2004) Critical care medicine in the United States 1985-2000: an analysis of bed numbers, use, and costs. Crit Care Med 32:1254-1259
13. Halpern NA, Pastores SM, Thaler HT, Greenstein RJ (2007) Critical care medicine use and cost among Medicare beneficiaries 1995-2000: major discrepancies between two United States federal Medicare databases. Crit Care Med 35:692-699

14. Coopersmith CM, Wunsch H, Fink MP, Linde-Zwirble WT, Olsen KM, Sommers MS, Anand KJ, Tchorz KM, Angus DC, Deutschman CS (2012) A comparison of critical care research funding and the financial burden of critical illness in the United States. Crit Care Med 40:1072-1079

15. Hernu R, Cour M, de la Salle S, Robert D, Argaud L (2015) Cost awareness of physicians in intensive care units: a multicentric national study. Intensive Care Med. doi:10.1007/s00134-015$3859-1$ 